\title{
Immunization with Recombinant Corynebacterium pseudotuberculosis Heat-Shock Protein (Hsp)-60 is Able to Induce an Immune Response in Mice, But Fails to Confer Protection Against Infection
}

\author{
Jean Marcel Rodrigues Pinho, ${ }^{1, \#}$, Fernanda Alves Dorella ${ }^{2, \#}$, Keila da Silva Coelho², \\ Cristina Toscano Fonseca ${ }^{1,3}$, Fernanda Caldas Cardoso ${ }^{1}$, Roberto Meyer ${ }^{4}$, \\ Ricardo Wagner Dias Portela ${ }^{4}$, Sergio Costa Oliveira ${ }^{1}$, \\ Anderson Miyoshi ${ }^{2}$, Vasco Azevedo ${ }^{*}, 2$
}

\author{
${ }^{I}$ Departamento de Bioquímica e Imunologia, Instituto de Ciências Biológicas, Universidade Federal de Minas Gerais, \\ Belo Horizonte - MG, Brazil \\ ${ }^{2}$ Departamento de Biologia Geral, Instituto de Ciências Biológicas, Universidade Federal de Minas Gerais, Belo \\ Horizonte - MG, Brazil \\ ${ }^{3}$ Centro de Pesquisas Rene Rachou, Fundação Oswaldo Cruz, Belo Horizonte-MG, Brazil \\ ${ }^{4}$ Departamento de Bio-interação, Universidade Federal da Bahia, Salvador - BA, Brazil
}

\begin{abstract}
Corynebacterium pseudotuberculosis is the etiological agent of caseous lymphadenitis (CLA), a chronic small ruminant's disease. C. pseudotuberculosis Hsp60 expressed in E. coli was purified and tested as a vaccine candidate against CLA. Immunization of BALB/c mice with recombinant Hsp60 (rHsp60) induced a significant anti-Hsp60 IgG response, with greater production of $\operatorname{IgG} 1$ than of IgG2a. Cell-mediated immune responses induced by immunization were characterized by elevated production of gamma interferon (IFN- $\gamma$ ) and interleukin (IL)-10, while IL-4 concentrations were not significantly increased. Otherwise, mice challenged with $10^{6}$ c.f.u. of a virulent $C$. pseudotuberculosis strain developed abscesses and other signs of morbidity at the site of inoculation. The rate of survival of the animals immunized with rHsp60 was slightly higher than that of mice immunized with PBS; however, all the animals died within two weeks after challenge. We concluded that subcutaneous administration of $\mathrm{rHsp} 60$ does not induce effective protection against intraperitoneal infection with C. pseudotuberculosis.
\end{abstract}

\section{INTRODUCTION}

Corynebacterium pseudotuberculosis, a facultative intracellular bacterium, is the etiological agent of caseous lymphadenitis (CLA), a chronic and contagious disease that affects sheep and goats worldwide [1-3]. CLA is characterized by the formation of abscesses, typically located in superficial lymph nodes and the lungs, resulting in significant economic losses [4-6]. Transmission among animals occurs mainly through contamination of superficial wounds, which can appear during common procedures, such as shearing, castration and ear tagging, or through injuries of the animal's bodies generated by other traumatic events. Not infrequently, contaminated sheep cough bacteria onto skin cuts of other sheep, constituting another means of transmission [3].

Treatment and control of this disease is difficult because the bacteria are protected inside granulomes, safe from effective concentrations of antimicrobial agents [7]. Consequently other treatment options, such as immunoprophylaxis, are

*Address correspondence to this author at the Departamento de Biologia Geral, Instituto de Ciências Biológicas, Universidade Federal de Minas Gerais, Belo Horizonte - MG, Brazil; Tel/Fax: 0055313409 2610;

E-mail: vasco@icb.ufmg.br

${ }^{\#}$ These authors share credit in this work for senior authorship. needed to control CLA. Various strategies have been tested to develop an efficient vaccine against $C$. pseudotuberculosis, including the use of attenuated and inactivated bacteria [8-12], and DNA-based vaccines [13]. Among the different formulations tested, the toxoid phospholipase D (PLD) is the most frequently used antigen; it induces partial protection in sheep and goats. However, many undesirable side effects are associated with the use of this exotoxin $[1,14,15]$; consequently, the search continues for identification of effective and safe C. pseudotuberculosis vaccine antigens.

Heat-shock proteins (HSPs), a highly conserved category of microbial and mammalian proteins, can elicit both humoral and cellular immune responses [16-18], which are crucial to initiate a specific response against pathogens. According van Eden [19], there are three factors to explain the immunogenicity of Hsps: (i) they are highly conserved molecules, consequently the immune response against conserved epitopes of non-related bacteria is more effective; (ii) they are highly expressed during stress, being easily recognized by the host's immune system; (iii) during infection, the chaperones can be associated to the released antigens during antimicrobial action, the complex antigen-Hsps is captured, processed and presented to immune system, generating an efficient response against the pathogen. 
Significant protection against bacterial infections has been achieved with vaccines made with HSPs [20-25], including Hsp65 from Mycobacterium leprae; this species is phylogenetically related to C. pseudotuberculosis [26].

All these statements encouraged us to test recombinant $C$. pseudotuberculosis Hsp60 (rHsp60) as an immunogen against CLA, in a murine model.

\section{METHODS}

\section{Mice}

BALB/c females, 6-8 weeks old, were obtained from the Federal University of Minas Gerais (UFMG) animal facility. This mouse strain was chosen due to its susceptibility to $C$. pseudotuberculosis infection [27-28].

\section{Bacterial Strains, Growth Conditions and Plasmids}

Escherichia coli Top10 was purchased from Invitrogen. C. pseudotuberculosis biovar ovis (T1 strain) was obtained from the Cellular and Molecular Genetics Laboratory's (UFMG) stock collection. Escherichia coli and C. pseudotuberculosis were aerobically grown in Luria Bertani (LB) and Heart and Brain Infusion (BHI) broths, respectively, at $37^{\circ} \mathrm{C}$. The pTOPO plasmid (Invitrogen) was used for cloning and sequencing of the $C$. pseudotuberculosis hsp60 gene. The pProEx-Hta plasmid (Gibco BRL) was used for production of the rHsp60 protein.

\section{Subcloning of the $C$. pseudotuberculosis hsp60 Gene}

Genomic DNA from C. pseudotuberculosis was isolated, as described by Pacheco et al. [29]. The C. pseudotuberculosis hsp60 gene was amplified by PCR from genomic DNA with the following primers: 5'- GGGGGATCCGATGGCAA AGCTGATTGCA-3' (sense orientation) and 5'- GGG $\underline{\underline{A A G}}$ CTTTTAGTGGTGGTGATGGTG-3' (antisense orientation), which include, respectively, BamHI and HindIII sites (underlined). The parameters for the PCR reaction were as follows: 1 cycle: $95^{\circ} \mathrm{C}, 5 \mathrm{~min} ; 29$ cycles: $95^{\circ} \mathrm{C}, 1 \mathrm{~min}, 58^{\circ} \mathrm{C}$, $40 \mathrm{~s}, 68^{\circ} \mathrm{C}, 2 \mathrm{~min} ; 1$ cycle: $68^{\circ} \mathrm{C}, 7 \mathrm{~min}$. The PCR fragment $(1,626 \mathrm{pb})$, corresponding to the amplified hsp60 gene, was isolated from agarose gels using the Concert ${ }^{\mathrm{TM}}$ Rapid Gel Extraction System (Gibco BRL) and digested with BamHI and HindIII (according to manufacturers recommendations). After DNA digestion with BamHI and HindIII, the digested DNA was inserted into a pTOPO plasmid that had been previously digested with these same enzymes, generating a pTOPOhsp60 construction. Subsequently, the hsp60 gene was sequenced using MegaSequencing Systems (GE Healthcare) and subcloned at the BamHI/HindIII sites, into the pProEx-HTa expression vector, generating the pPROExHTahsp60 construction. Constructs were transformed into $E$. coli electrocompetent cells, according to standard procedures [30], using the gene Pulser System ${ }^{\mathrm{TM}}$ (Bio-Rad). Escherichia coli transformants harboring the constructed plasmids were screened on LB agar plates containing ampicillin $\left(100 \mu \mathrm{g} \mathrm{ml}^{-1}\right)$ and X-Gal $\left(40 \mu \mathrm{g} \mathrm{ml}^{-1}\right)$. The full-length sequence of C. pseudotuberculosis hsp60 DNA was deposited in GenBank, accession number AY_781285.

\section{Expression and Purification of Recombinant Hsp60}

The recombinant Hsp60 was expressed in a prokaryotic system using the pProEX-Hta expression vector. Proteins are expressed with an in-frame six-histidine $\mathrm{N}$-terminal tag in this expression vector. An E. coli Top 10 culture $(500 \mathrm{ml})$ containing the recombinant plasmid was grown at $37^{\circ} \mathrm{C}$ to an optical density at $600 \mathrm{~nm}$ of 0.5 , and expression of rHsp60 was induced by $1 \mathrm{mM}$ IPTG. After $4 \mathrm{~h}$ of induction, the bacterial cells were harvested by centrifugation at $4,000 \mathrm{~g}$ for $20 \mathrm{~min}$. The pellet was resuspended in $35 \mathrm{ml}$ of $10 \mathrm{mM}$ $\mathrm{Na}_{2} \mathrm{HPO}_{4}, 10 \mathrm{mM} \mathrm{NaH} \mathrm{PO}_{4}, 0.5 \mathrm{M} \mathrm{NaCl}$ and $10 \mathrm{mM}$ imidazole. Subsequently, the cells were submitted to three cycles of sonication lasting $30 \mathrm{~s}$ each and centrifuged at $5400 \mathrm{~g}$ for $20 \mathrm{~min}$. The rHsp60 was recovered as inclusion bodies and solubilized in $50 \mathrm{ml}$ of $8 \mathrm{M}$ urea, $10 \mathrm{mM} \mathrm{Na}_{2} \mathrm{HPO}_{4}, 10 \mathrm{mM}$ $\mathrm{NaH}_{2} \mathrm{PO}_{4}, 0.5 \mathrm{M} \mathrm{NaCl}$, and $10 \mathrm{mM}$ imidazole. The protein was purified by affinity chromatography on a Ni-Sepharose column using an AKTAexplorer chromatograph (GE Healthcare) under denaturing conditions, according to the manufacturer's protocol. Fractions containing rHsp60 were pooled and dialyzed against decreasing concentrations of urea $(6 \mathrm{M}, 4 \mathrm{M}, 2 \mathrm{M}$ and $1 \mathrm{M})$ in PBS buffer, followed by dialysis against PBS buffer. The dialyses were carried out at $4^{\circ} \mathrm{C}$ using a Spectra/Por2 membrane (6 to $8 \mathrm{kDa}$; Spectrum Medical). The purity of the rHsp60 was checked on $12 \%$ SDS-PAGE, followed by Coomassie blue staining [30], and protein concentration was quantified using the Bradford method [31]. This recombinant protein was used as an antigen for experimental immunization of the mice.

\section{Immunoblotting}

The polyacrylamide gel of purified rHsp60 was electroblotted onto a nitrocellulose membrane (Amersham Biosciences), based on Towbin et al. [32]. The membrane was blocked with TBS-T $(0.5 \mathrm{M} \mathrm{NaCl}, 0.02 \mathrm{M}$ Tris [ $\mathrm{pH} 7.5]$, $0.05 \%(\mathrm{w} / \mathrm{v})$ Tween 20) containing 10\% (w/v) skimmed milk powder for $16 \mathrm{~h}$ at room temperature. Subsequently, the membrane was incubated in a 1:2000 dilution of mouse alkaline phosphatase (AP) conjugated anti 6xHis antibody (Invitrogen) in TBS-T plus $10 \%(\mathrm{w} / \mathrm{v})$ skimmed milk powder for $1 \mathrm{~h}$ at room temperature. After three washes with TBS-T, the blot was developed using NBT (nitroblue tetrazolium chloride) and BCIP (5-bromo-4-chloro-3-indolyl-1-phosphate) detection reagents (Gibco BRL), according to the manufacturer's protocol (Gibco BRL). After the alkaline phosphatase reaction had developed, the membrane was washed with distilled water and dried on filter paper.

\section{Immunization Protocol}

Two groups of 5 mice each were immunized subcutaneously in the nape of the neck on days 0, 15 and 30. Each animal of the experimental group was injected with $200 \mu \mathrm{l}$ of a formulation containing $25 \mu \mathrm{g}$ of rHsp60 in complete Freund's adjuvant during the first immunization and $25 \mu \mathrm{g}$ of rHsp60 in incomplete Freund's adjuvant during the second and third immunizations. The control animals underwent the same vaccination protocol, but with PBS and without rHsp60. Blood samples were collected from the retro-orbital sinus of each mouse 15 days after each dose of the vaccine. Sera samples were stored at $20^{\circ} \mathrm{C}$ until use.

\section{Challenge of Mice with Virulent $C$. pseudotuberculosis}

Three weeks after the last immunization, mice were challenged via intraperitoneal inoculation with $1 \times 10^{6}$ c.f.u. of virulent $C$. pseudotuberculosis. The protection level was 
evaluated by the survival rate of the rHsp60 vaccinated group, compared to the control group. Mice were killed by cervical dislocation when moribund.

\section{Analysis of Humoral Responses to rHsp60}

Sera obtained from five mice of each group (rHsp60 vaccinated and PBS control groups) were collected two weeks after each immunization. Detection of specific antiHsp60 antibodies was performed by ELISA. Briefly, Maxisorp 96-well microtiter plates (Nunc) were coated with $5 \mu \mathrm{g}$ rHsp60 $\mathrm{ml}^{-1}$ in carbonate-bicarbonate buffer, $\mathrm{pH}$ 9.6, (100 $\mu \mathrm{l} / \mathrm{well})$ for $16 \mathrm{~h}$ at $4^{\circ} \mathrm{C}$. The plates were then washed with PBS-T (PBS plus $0.05 \%(\mathrm{v} / \mathrm{v})$ Tween 20) and blocked for 2 $\mathrm{h}$ at room temperature with $200 \mu \mathrm{l}$ per well of PBS-T plus $10 \%(\mathrm{v} / \mathrm{v})$ fetal bovine serum. Sera from immunized mice were diluted 1:200 in PBS-T, added to plates $(100 \mu \mathrm{l} /$ well $)$, and incubated for $1 \mathrm{~h}$ at room temperature. Plate-bound antibody was detected by peroxidase-conjugated anti-mouse IgG (Promega), IgG1 (Sigma) and IgG2a (Sigma) diluted 1:5000, 1:5000 and 1:2000, respectively, in PBS-T. The colorimetric reaction was developed by addition of $100 \mu 1$ per well of 200 pmol o-phenylenediamine (OPD, Sigma) in citratephosphate buffer, $\mathrm{pH} 5.0$, plus $0.04 \%(\mathrm{v} / \mathrm{v}) \mathrm{H}_{2} \mathrm{O}_{2}$, for $10 \mathrm{~min}$ and stopped with $50 \mu \mathrm{l}$ of $5 \%(\mathrm{v} / \mathrm{v})$ sulfuric acid per well. The absorbance was read in a spectrophotometer (Bio-rad) at $492 \mathrm{~nm}$.

\section{Cytokine Analysis}

One week after the last immunization, five mice of the rHsp60 immunized group, non-challenged, were sacrificed. Splenocytes isolated from the macerated spleens were washed twice in sterile PBS and then adjusted to 1 X10 $10^{6}$ cells $\mathrm{mL}^{-1}$ in RPMI 1640 medium (Gibco) supplemented with $10 \%(\mathrm{v} / \mathrm{v})$ fetal bovine serum, $100 \mathrm{U}$ penicillin $\mathrm{G}$ sodium $\mathrm{ml}^{-1} 100 \mu \mathrm{g}$ streptomycin sulfate $\mathrm{ml}^{-1}{ }^{-1} 250 \mathrm{ng}$ amphotericin $\mathrm{B} \mathrm{ml}^{-1}$ and $10 \mu \mathrm{g}$ polymyxin $\mathrm{B} \mathrm{ml}^{-1}$. Splenocytes were maintained in RPMI medium alone (negative control) or stimulated with rHsp60 $\left(50 \mu \mathrm{g} \mathrm{ml}^{-1}\right)$, concanavalin A (ConA) $(5$ $\mu \mathrm{g} \mathrm{ml}^{-1}$ ) or purified E. coli LPS (Sigma) at the same concentration of endotoxin measured in rHSP60 $\left(2.5 \mu \mathrm{g} \mathrm{ml}^{-1}\right)$. The 96-well plates (Nunc) were maintained in an incubator at $37^{\circ} \mathrm{C}$ with $5 \% \mathrm{CO}_{2}$. Culture supernatants were collected after $24 \mathrm{~h}$ of ConA stimulation, and $48 \mathrm{~h}$ (IL-4) or $72 \mathrm{~h}$ (IFN- $\gamma$ and IL-10) after rHsp60 treatment. Assays for measuring IL-4, IFN- $\gamma$ and IL-10 were performed using Duoset ELISA kits (R\&D Diagnostic), according to the manufacturer's protocol.

\section{Statistical Analysis}

Statistical analysis was performed with the Student's ttest or ANOVA using the computer software package GraphPad Prism 2.0 (GraphPad Software).

\section{RESULTS AND DISCUSSION}

\section{Production of Recombinant Hsp60}

To confirm that C. pseudotuberculosis $\mathrm{rHsp60}$ was expressed in E. coli as a 6xHIS-tag fusion, SDS-PAGE (Fig. 1a) and Western blot (Fig. 1c) analyses were performed, revealing a band of approximately $60 \mathrm{kDa}$, corresponding to the estimated molecular mass for rHsp60 (58.2 kDa). This recombinant protein was recovered as inclusion bodies and purified under denaturing conditions in $8 \mathrm{M}$ urea using a nickel affinity column (Fig. 1b). Refolding in renaturing
PBS buffer resulted in loss of protein in the precipitated form; however, it yielded enough soluble recombinant protein $\left(1.6 \mu g \mu^{-1}\right)$ for the immunization experiments.

(a)

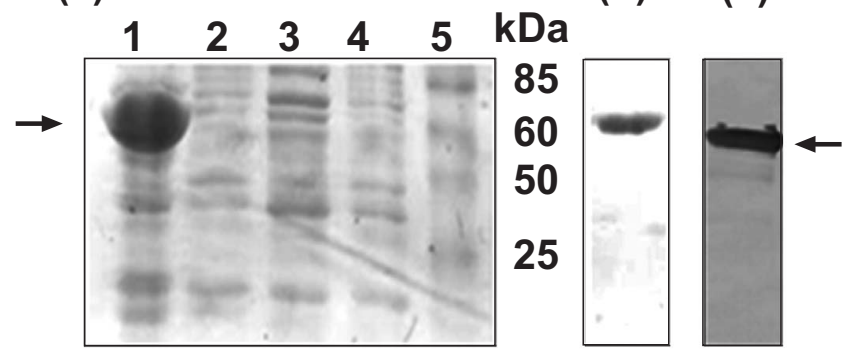

Fig. (1). SDS-PAGE and Western blot analysis of the recombinant HIS-Hsp60 fusion protein (rHsp60). (a) Coomassie Blue stained SDS-12\% PAGE profile of E. coli lysate expressing the pProExHta-hsp60 construct. Pellet and supernatant of the culture induced by IPTG (lanes 1 and 2, respectively). Pellet and supernatant of the uninduced culture (lanes 3 and 4, respectively). Molecular weight marker (lane 5). (b) Coomassie Blue stained SDS-12\% PAGE profile of the purified rHsp60. (c) Western blot of the purified rHsp60 using anti-6xHIS antibody. Arrow indicates the rHsp60.

\section{Humoral Responses to rHsp60}

In order to assay for specific anti-rHsp60 IgG antibodies, sera from the vaccinated mice were tested by ELISA. Recombinant Hsp60 vaccinated mice developed high and significant titers of IgG anti-rHsp60 compared to the PBS control group, mainly after the second immunization (Fig. 2). The same high titers were maintained after the third immunization, demonstrating that the immunization with rHsp60 stimulated the production of specific antibodies.

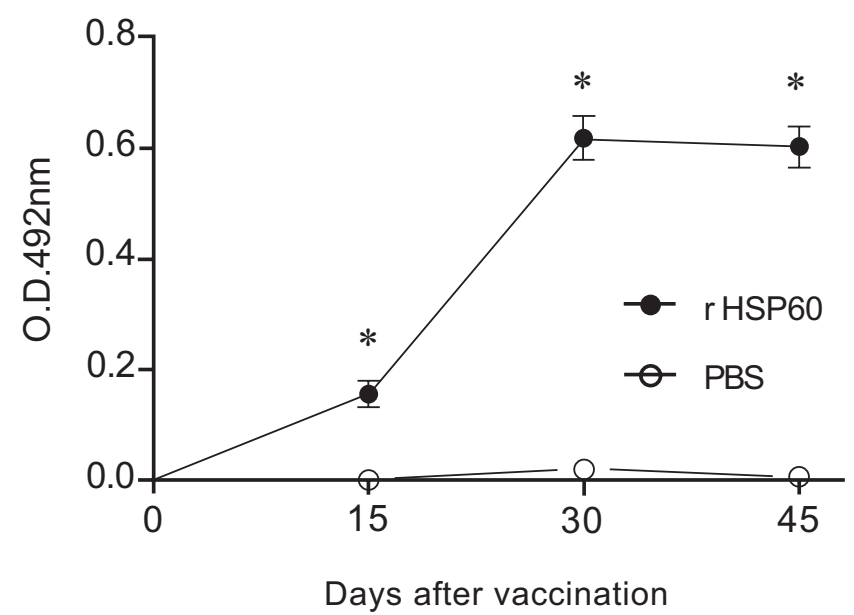

Fig. (2). Kinetics of anti-rHsp60 specific IgG responses in rHsp60immunized mice. Sera of five immunized mice were collected at days 15, 30 and 45 after the first immunization (day 0) and assayed by ELISA for anti-Hsp60 antibodies. Results are presented as means of each immunization group. Error bars indicate standard deviations of the means. "Significantly different from the PBS control group $(\mathrm{p}<0.05)$.

The IgG1 and IgG2a subclasses were also analyzed in order to determine the pattern of immune response. Immunization with rHsp60 induced production of both IgG1 (Fig. 3a) and IgG2a (Fig. 3b) anti-Hsp60 antibodies. However, higher levels of specific IgG1anti-Hsp60 were produced than 
of IgG2a. Similar results were obtained after BALB/c immunization with Rhodococcus equi rHsp60, a C. pseudotuberculosis philogenetically related microorganism [33].

(a)

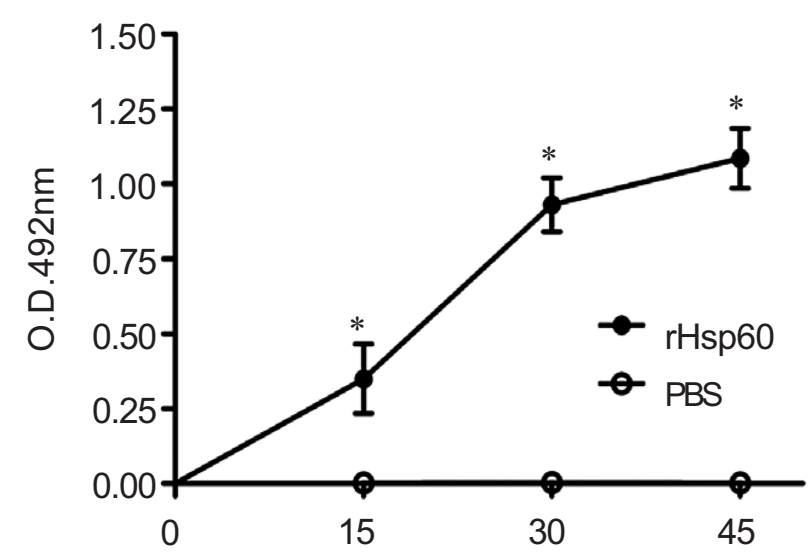

Days after vaccination

(b) $\lg$ G2a

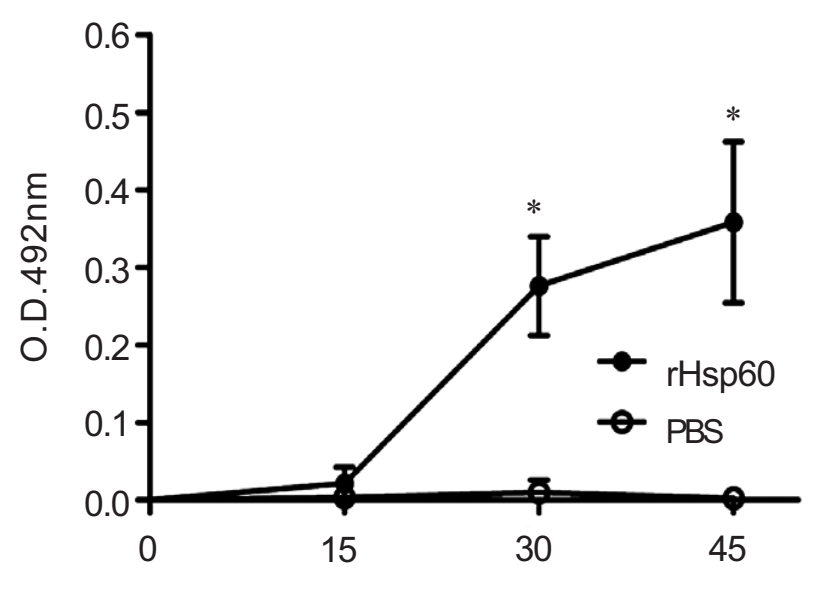

Days after vaccination

Fig. (3). Levels of IgG1 and IgG2a isotypes following rHsp60 immunization. Kinetics of anti-rHsp60 specific IgG1 (a) and IgG2a (b). Results are presented as means of each immunized group $(\mathrm{n}=5)$. Error bars indicate standard deviations of the means. * Significantly different from the PBS control group $(\mathrm{p}<0.05)$.

\section{Cytokine Profile Induced Following rHsp60 Vaccination}

Production of IFN- $\gamma$, IL-4 and IL-10 in splenocyte culture supernatants from immunized mice was measured by ELISA (Fig. 4). We observed high levels of IFN- $\gamma$ production in cells stimulated with rHsp60 and these levels were significantly greater than in cells cultured with medium and LPS alone. The IL-10 production was significantly elevated too, while IL-4 production levels were almost undetectable. This cytokine profile, with the production of antagonistic cytokines IFN- $\gamma$ and IL-10, was not expected because the high production of IL-10 inhibits the production of IFN- $\gamma$. We suggest that the cellular response was immunomodulated by rHsp60. The epitope recognition produced an inflamma- tory response, characterized by IFN- $\gamma$ production. Otherwise, the immune system could recognize conserved sequences between prokaryotes and eukaryotes Hsps, giving rise to an immune suppressor response, with IL-10 production [34-35].

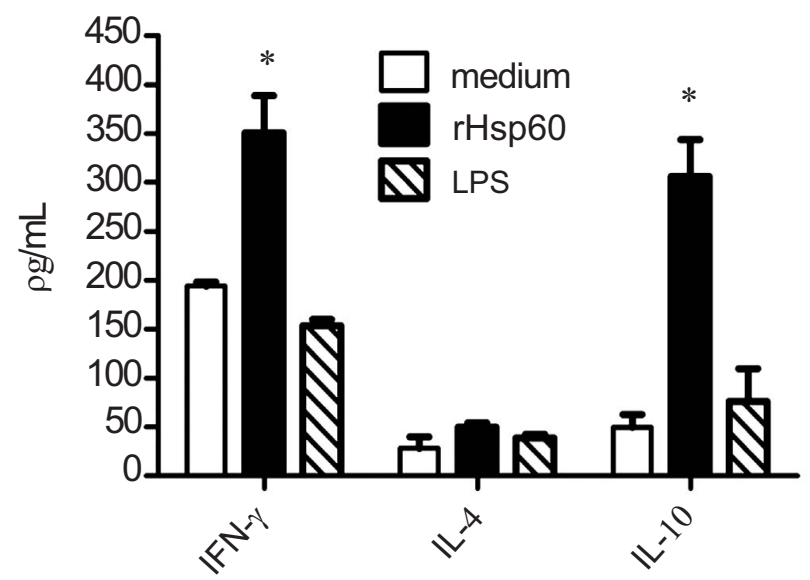

Fig. (4). Cytokine profile of mice immunized with rHsp60. One week after the third immunization (day 45) splenocytes were isolated and assayed for production of IFN- $\gamma$, IL- 4 and IL-10 in response to rHsp60 $\left(50 \mu \mathrm{g} \mathrm{ml}^{-1}\right)$, and LPS $\left(2.5 \mu \mathrm{g} \mathrm{ml}^{-1}\right)$ or RPMI medium alone (controls). The results are presented as means of each group $(n=5)$. Error bars indicate standard deviations of the means. " Significantly different from the medium and LPS control groups $(\mathrm{p}<0.05)$.

\section{Protective Efficacy of rHsp60 Against Challenge}

Three weeks after the last immunization, BALB/c mice were challenged with virulent $C$. pseudotuberculosis. Both vaccinated and control groups presented signs of morbidity and abscesses. All of the mice immunized with the PBS control were killed by cervical dislocation, due these morbidity signs, by day 3 . The animals immunized with rHsp60 lived slightly longer, with $100 \%$ mortality occurring by day 11 (Fig. 5). Although animals immunized with recombinant protein had presented a survival rate higher than control group, the time of survival was short to consider rHSp60 as a protective vaccine. These experiments were carried out twice, giving similar results.

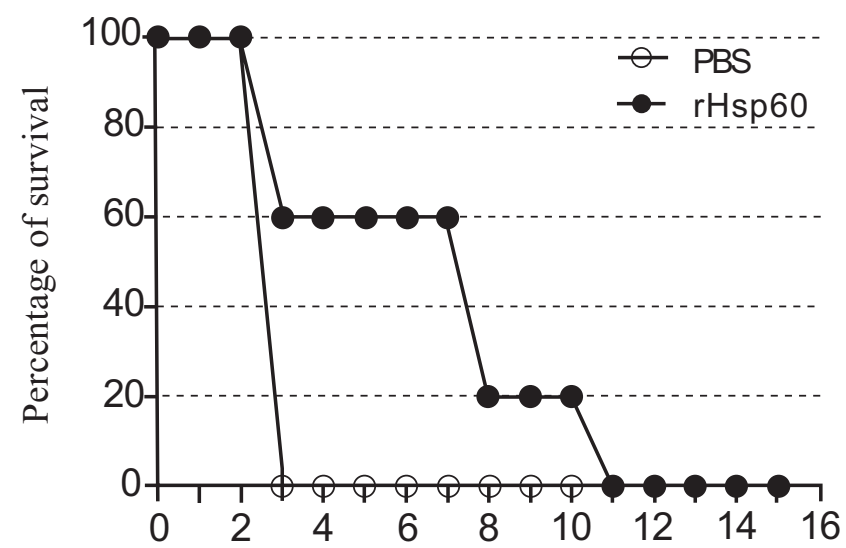

Days after Challenge

Fig. (5). Survival of BALB/c mice infected intraperitoneally with $1 \times 10^{6}$ c.f.u. of virulent Corynebacterium pseudotuberculosis. The data show a representative experiment, using five mice for each group, which were monitored daily for survival. 


\section{CONCLUSION}

We concluded that subcutaneous administration of rHsp60 does not induce effective protection against intraperitoneal infection with $C$. pseudotuberculosis. Turner et al. [36] found similar results with vaccines directed against the Hsp60 molecule of $M$. tuberculosis. Immunity to CLA has been attributed to both a strong humoral component and to cell-mediated immunity mechanisms. Induction of a Th1type T-cell response, characterized by IFN- $\gamma$ production [3739 ], has been found to be involved in protection against infection. In our study, vaccination with rHsp60 induced high levels of IL-10 and IFN- $\gamma$, suggesting an immunomodulatory response. This could be the reason why our immunization procedure was unable to confer protection, since IL-10 down-regulates the production of other cytokines, such as IFN- $\gamma[40-43]$.

Despite the successful utilization of rHsp60 in immunization against different microorganisms [20, 44], there are some reports where the protection did not occur $[45,46]$. There is not an explication why proteins highly conserved, like Hsp60, acts differently when used as vaccinal antigens. Moreover, is difficult to establish a comparison among Hsp60s from different microorganisms used as antigens since the protocols of immunization, doses and inoculation route were diverse.

Other strategies could be used in order to improve the protective response provided by vaccination with $C$. pseudotuberculosis Hsp60. Co-administration of immunostimulatory molecules, such as IL-12, improves the immune response and directs it towards a Th1 phenotype that is able to elicit protection against challenge by Yersinia enterocolitica [20]. Other alternatives consist include a DNA based-vaccine and immunization with an attenuated C. pseudotuberculosis strain overexpressing Hsp60. Besides, we can suggest the utilization of rHsp60 as an adjuvant in immunization with attenuated or inactivated C. pseudotuberculosis or even combined with other proteins of this bacterium.

\section{ACKNOWLEDGEMENTS}

Research supported by CNPq (Conselho Nacional de Desenvolvimento Científico e Tecnológico, Brasil), FINEP \# 01.04.760.00 (Financiadora de Estudos e Projetos - Ministério da Ciência e Tecnologia, Brazil), CAPES (Coordenação de Aperfeiçoamento de Pessoal de Nível Superior) and FAPEMIG (Fundação de Amparo a Pesquisa de Minas Gerais).

\section{REFERENCES}

[1] Williamson LH. Caseous lymphadenitis in small ruminants. Vet Clin North Am Food Anim Pract 2001; 17: 359-71.

[2] Paton MW, Walker SB, Rose IR, et al. Prevalence of caseous lymphadenitis and usage of caseous lymphadenitis vaccines in sheep flocks. Aust Vet J 2003; 81: 91-5.

[3] Dorella FA, Pacheco LGC, Oliveira SC, et al. Corynebacterium pseudotuberculosis: microbiology, biochemical properties, pathogenesis and molecular studies of virulence. Vet Res 2006; 37: 20118 .

[4] Batey RG. Pathogenesis of caseous lymphadenitis in sheep and goats. Aust Vet J 1986; 63: 269-72.

[5] Paton MW, Rose IR, Hart RA, et al. New infection with Corynebacterium pseudotuberculosis reduces wool production. Aust Vet J 1994; 71: 47-9.

[6] Arsenaut J, Girard C, Dubreuil P, et al. Prevalence of and carcass condemnation from maedi-visna, paratuberculosis and caseous lymphadenitis in culled sheep from Quebec, Canada. Prev Vet Med 2003; 59: 67-81.

Olson ME, Ceri H, Morck DW, et al. Biofilm bacteria: formation and comparative susceptibility to antibiotics. Can J Vet Res 2002; 66: 86-92.

[8] Leamaster BR, Shen DT, Gorham JR, et al. Efficacy of Corynebacterium pseudotuberculosis bacterin for the immunologic protection of sheep against development of caseous lymphadenitis. Am J Vet Res 1987; 48: 869-72.

[9] Holstad G. Corynebacterium pseudotuberculosis infection in goats. IX. The effect of vaccination against natural infection. Acta Vet Scand 1989; 30: 285-93.

[10] Brogden KA, Chedid L, Cutlip RC, et al. Effect of muramyl dipeptide on immunogenicity of Corynebacterium pseudotuberculosis whole-cell vaccines in mice and lambs. Am J Vet Res 1990; 51: 200-2.

[11] Eggleton DG, Middleton HD, Doidge CV, et al. Immunization against ovine caseous lymphadenitis: comparison of Corynebacterium pseudotuberculosis vaccines with and without bacterial cells. Aust Vet J 1991; 68: 317-9.

[12] Ellis JA, Hawk DA, Mills KW, et al. Antigen specificity and activity of ovine antibodies induced by immunization with Corynebacterium pseudotuberculosis culture filtrate. Vet Immunol Immunopathol 1991; 28: 303-16.

[13] Chaplin PJ, De Rose R, Boyle JS, et al. Targeting improves the efficacy of a DNA vaccine against Corynebacterium pseudotuberculosis in sheep. Infect Immun 1999; 67: 6434-8.

[14] Piontkowski MD, Shivvers DW. Evaluation of a commercially available vaccine against Corynebacterium pseudotuberculosis for use in sheep. J Am Vet Med Assoc 1998; 212: 1765-8.

[15] Standford K, Brogden KA, Clelland LA, et al. The incidence of caseous lymphadenitis in Alberta sheep and assessment of impact by vaccination with commercial and experimental vaccines. Can J Vet Res 1998; 62: 38-43.

[16] Suzue K, Young RA. Heat shock proteins as immunological carriers and vaccines. EXS 1996; 77: 451-65.

[17] Zügel U, Kaufmann SH. Immune response against heat shock proteins in infectious diseases. Immunobiology 1999; 201: 22-35

[18] Wallin RPA, Lundqvist A, Moré SH, et al. Heat-shock proteins as activators of the innate immune system. Trends Immunol 2002; 23: 130-5.

[19] van Eden W, van der Zee R, Prakken B. Heat shock proteins induce T-cell regulation of chronic inflammation. Nature Rev Immunol 2005; 5: 318-30

[20] Noll A, Autenrieth IB. Immunity against Yersinia enterocolitica by vaccination with Yersinia HSP60 immunostimulating complexes or Yersinia HSP60 plus interleukin-12. Infect Immun 1996; 64: 295561.

[21] Bonato VLD, Lima VMF, Tascon RE, et al. Identification and characterization of protective $\mathrm{T}$ cells in Hsp65 DNA-vaccinated and Mycobacterium tuberculosis-infected mice. Infect Immun 1998; 66: 169-75.

[22] Lowrie DB, Tascon RE, Bonato VL, et al. Therapy of tuberculosis in mice by DNA vaccination. Nature 1999; 400: 269-71.

[23] Silva CL. The potential use of heat-shock proteins to vaccinate against mycobacterial infections. Microbes Infect 1999; 1: 429-35.

[24] Lima KM, dos Santos SA, Santos RR, et al. Efficacy of DNAhsp65 vaccination for tuberculosis varies with method of DNA introduction in vivo. Vaccine 2003; 22: 49-56.

[25] Silva CL, Bonato VL, Coelho-Castelo AA, et al. Immunotherapy with plasmid DNA encoding mycobacterial Hsp65 in association with chemotherapy is a more rapid and efficient form of treatment for tuberculosis in mice. Gene Ther 2005; 12: 281-7.

[26] Pascual C, Lawson PA, Farrow JA, et al. Phylogenetic analysis of the genus Corynebacterium based on 16S rRNA gene sequences. Int J Syst Bacteriol 1995; 45: 724-8.

[27] Muckle CA, Gyles CL. Relation of lipid content and exotoxin production to virulence of Corynebacterium pseudotuberculosis in mice. Am J Vet Res 1983; 44: 1149-53.

[28] Batey RG. Aspects of pathogenesis in a mouse model of infection by Corynebacterium pseudotuberculosis. Aust J Exp Biol Med Sci 1986; 64: 237-49.

[29] Pacheco LG, Pena RR, Castro TL, et al. Multiplex PCR assay for identification of Corynebacterium pseudotuberculosis from pure cultures and for rapid detection of this pathogen in clinical samples. J Med Microbiol 2007; 56: 480-6. 
[30] Sambrook J, Fritsch EF, Maniatis T. Molecular Cloning: A Laboratory Manual. $2^{\text {nd }}$ Ed. Cold Spring Harbor Laboratory, Cold Spring Harbor: New York 1989.

[31] Bradford MM. A rapid and sensitive method for the quantitation of microgram quantities of protein utilizing the principle of proteindye binding. Anal Biochem 1976; 72: 48-254.

[32] Towbin H, Staehelin T, Gordon J. Electrophoretic transfer of proteins from polyacrylamide gels to nitrocellulose sheets: procedure and some applications. Proc Natl Acad Sci USA 1979; 76: 4350-4.

[33] Vanniasinkam T, Barton MD, Heuzenroeder MW. The immunogenicity of Rhodococcus equi GroEL2 based vaccines in a murine model. Vet Immunol Immunopathol 2004; 98: 91-100.

[34] Mustafa AS. Development of new vaccines and diagnostic reagents against tuberculosis. Mol Immunol 2002; 39: 113-9.

[35] van Eden W, Koets A, van Kooten P, et al. Immunopotentiating heat shock proteins: negociators between innate danger and control of autoimmunity. Vaccine 2003; 21: 897-901.

[36] Turner OC, Roberts AD, Frank AA, et al. Lack of protection in mice and necrotizing bronchointerstitial pneumonia with bronchiolitis in guinea pigs immunized with vaccines directed against the hsp60 molecule of Mycobacterium tuberculosis. Infect Immun 2000; 68: 3674-9.

[37] Hodgson AL, Tachedjian M, Corner LA, et al. Protection of sheep against caseous lymphadenitis by use of a single oral dose of live recombinant Corynebacterium pseudotuberculosis. Infect Immun 1994; 62: 5275-80.

[38] Walker J, Jackson HJ, Eggleton DG, et al. Identification of a novel antigen from Corynebacterium pseudotuberculosis that protects sheep against caseous lymphadenitis. Infect Immun 1994; 62: 2562-7.

[39] Simmons CP, Dunstan SJ, Tachedjian M, et al. Vaccine potential of attenuated mutants of Corynebacterium pseudotuberculosis in sheep. Infect Immun 1998; 66: 474-9.

[40] Boussiotis VA, Tsai EY, Yunis EJ, et al. IL-10-producing T cells suppress immune responses in anergic tuberculosis patients. J Clin Invest 2000; 105: 1317-25.

[41] Shaw T, Thomas LH, Friedland JL. Regulation of IL-10 secretion after phagocytosis of Mycobacterium tuberculosis by human monocytic cells. Cytokine 2000; 12: 483-6.

[42] Moore KW, de Wall MR, Coffman RL, et al. Interleukin-10 and the Interleukin-10 receptor. Annu Rev Immunol 2001; 19: 683-765.

[43] de la Barrera S, Aleman M, Musella R, et al. IL-10 down-regulates costimulatory molecules on Mycobacterium tuberculosis-pulsed macrophages and impairs the lytic activity of CD4 and CD8 CTL in tuberculosis patients. Clin Exp Immunol 2004; 138: 128-38.

[44] Yamaguchi H, Osaki T, Taguchi $\mathrm{H}$, et al. Effect of bacterial flora on postimmunization gastritis following oral vaccination of mice with Helicobacter pilori heat shock protein 60. Clin Diagn Laborat Immunol 2003; 10: 808-12.

[45] Bae Je, Schurig GG, Toth TE. Mice immune responses to Brucella abortus heat shock proteins use of baculovirus recombinantexpressing whole insect cells, purified Brucella abortus recombinant proteins, and a vaccinia virus recombinant as immunogens. Vet Microbiol 2002; 14: 189-202.

[46] Héchard C, Grépinet O, Rodolakis A. Molecular cloning of the Chamydophila abortus groEL gene and evaluation of its protective efficacy in a murine model by genetic vaccination. J Med Microbiol 2004; 53: 861-8.

(C) Pinho et al.; Licensee Bentham Open.

This is an open access article licensed under the terms of the Creative Commons Attribution Non-Commercial License (http: //creativecommons.org/licenses/by$\mathrm{nc} / 3.0 /$ ) which permits unrestricted, non-commercial use, distribution and reproduction in any medium, provided the work is properly cited. 